\title{
Closed-loop target-controlled infusion system for propofol guided by bispectral index applied in patients undergoing shoulder arthroscopy in the beach chair position- a randomized controlled trial
}

\section{Zhao Zhao}

Shenzhen Second People's Hospital

Junjie Li

Shenzhen Second People's Hospital https://orcid.org/0000-0003-1226-5404

\section{Yang Fang}

Shenzhen Second People's Hospital

Luo Nanbo

Shenzhen Second People's Hospital

\section{Yang Han}

Shenzhen Second People's Hospital

\section{Yang Xinping}

Shenzhen Second People's Hospital

\section{Peng Liangquan}

Shenzhen Second People's Hospital

\section{Lu Wei}

Shenzhen Second People's Hospital

\section{Guangguang Fang}

Shenzhen Second People's Hospital

\section{Wang Daping}

Shenzhen Second People's Hospital

Zhiheng Liu ( $\square$ zhiheng_liu_tongji@163.com )

https://orcid.org/0000-0002-2823-543X

\section{Research article}

Keywords: Propofol, Closed-loop Target Controlled Infusion System, Shoulder Arthroscopy, Beach Chair Position, BIS

Posted Date: March 25th, 2020 
DOI: https://doi.org/10.21203/rs.3.rs-19259/v1

License: (c) (1) This work is licensed under a Creative Commons Attribution 4.0 International License. Read Full License 


\section{Abstract}

Background To compare the efficacy of anesthetic depth control using closed-loop and open-loop target controlled infusion (TCl) system of propofol guided by BIS in patients undergoing shoulder arthroscopy in the beach chair position (BCP).

Methods 120 patients underwent shoulder arthroscopy surgery in the BCP were randomized into two groups, the open-loop (O) group and the closed-loop (C) group. During the maintenance phase, BIS value was used as the feedback variable for TCl system of propofol in both groups. The Global score (GS) and the percentage of adequate anesthesia, the frequency of propofol regulation, and consumption of propofol were calculated. The MMSE scores of the day before and 1 day after surgery, serum GFAP and S100B proteins before anesthesia, after extubation and 1 day after surgery were compared.

Results The GS and the proportion of appropriate anesthesia time were better in the group C. The percentage of overshoot time was lower in the group $\mathrm{C}$. The frequency of propofol regulation was observed higher in the group $\mathrm{C}$. Propofol consumption in the group $\mathrm{C}$ was significantly lower than that in the group 0 . The MMSE scores, the GFAP and S100B protein concentrations had no significant difference between the two groups.

Conclusion Propofol administration using close-loop TCI system guided by BIS may increase the percentage of adequate anesthesia and shorten the percentage of overshoot time compared with openloop TCl model in anesthesia maintenance phase in patients undergoing shoulder arthroscopy in the BCP, and do not increase the risk of POCD.

\section{Background}

Electroencephalographic (EEG) activity can provide a reliable basis for a substitute measurement of hypnosis, thus the Bispectral Index (BIS), an EEG monitor, has been proven helpful to titrate hypnotic drugs. The basis for EEG-based depth-of-anesthesia monitoring is the behavioral correlates and EEG changes occurring with increasing anesthetic depth[1]. Closed-loop target controlled infusion system is a closed loop anesthesia delivery system guided by BIS and automatically regulates the propofol infusion to maintain BIS within the set target range[2]. It has been reported to allow the automated delivery of propofol and maintain BIS values in predetermined range better than manual administration during general anesthesia[3].

Although closed-loop TCl systems for propofol guided by BIS has many advantages for depth-ofanesthesia maintenance, those results were obtained in the supine position, and whether the same story might happen on the operations in BCP remains unknown.

Beach chair position is a deformation of the supine surgical position. After placement of BCP, the patient's head and neck form an angle of $90^{\circ} \sim 110^{\circ}$ with the horizontal position. Alperin et al[4] monitored the blood flow and cerebrospinal fluid in the supine position and head high positions by MRI, and the 
patients in this special position could cause a significant decrease in intracranial blood flow and cerebrospinal fluid. Changes in intracranial blood flow may cause changes in EEG signals and EEG waveform.

Therefore, the main aim of this study was to compare BIS profiles (percentage of time with desired values) between the closed-loop TCl systems of propofol guided by BIS and the open-loop TCl guided by BIS in BCP. In addition, we aimed to study if different propofol infusion system have any effects on the incidence of postoperative cognitive dysfunction and intraoperative hemodynamic fluctuations.

\section{Materials And Methods}

Study design

This is a prospective randomized controlled study, which was approved by the Ethics Committee of the Second People's Hospital of Shenzhen in August 2017, and was registered at Chictr.org.cn. (ID: ChiCTRINR-17012557). Informed written consent was obtained from all patients, and the study was based on the principles of the Declaration of Helsinki for medical research involving human subjects.

\section{Participants}

From Sept. 2017 to March 2018, 120 patients were included in this study. ASA I/II patient aged 1665 years scheduled for shoulder arthroscopy in BCP were randomized equally into either the group $\mathrm{C}$ or the group $\mathrm{O}$ using computer generated random numbers. The random allocation sequence was conducted by a team member who was not related to operation and patient assessment. And the same member prepared opaque envelopes in which the intervention information was concealed. Before interscalene brachial plexus block, these envelopes were opened. Patients were excluded from the study if with a cardiac pacemaker, communication difficulties, history of mental illness, craniocerebral surgery, coagulation dysfunction, diabetes mellitus with peripheral neuropathy, or participating in other clinical trials.

Interventions

Patients were monitored in the operating room as per standard procedure, with non-invasive blood pressure (NIBP), heart rate (HR), electrocardiogram (ECG), pulse oximetry $\left(\mathrm{SpO}_{2}\right)$ and invasive blood pressure (IBP) and BIS (A-2000XP BIS, Aspect Medical system, Dublin, Ireland) with electrodes placed on patients' forehead. Ultrasound-guided interscalene brachial plexus block was performed before anesthesia induction. All patients received TCl propofol (the initial target concentrations in the plasma was 3 to $4 \mathrm{ug} / \mathrm{ml}$ ) and remifentanil (the initial target concentrations in the effect-side was $4 \mathrm{ng} / \mathrm{ml}$ ) until the BIS maintained at $<60$ for 30 seconds, followed by propofol administration either by open-loop in the group 0 or closed-loop in the group C. The parameters of TIVA-TCI described by Marsh et al.[5] and Minto et al.[6] were used for propofol and remifentanil, respectively. 
The rocuronium was used after the loss of consciousness, and the induction dose was $0.6 \mathrm{mg} / \mathrm{kg}$. Endotracheal intubation was performed after muscle relaxation.

During the maintenance phase, in order to maintain the BIS at about 50 (40 to 60), the target concentration of propofol was regulated manually in the group 0 and automatically by the system in the group C. Both groups were treated with remifentanil, and the target concentration ( 3 to $5 \mathrm{ng} / \mathrm{ml}$ ) was determined by the clinical judgment of the anesthesiologists.

Surgery was performed in BCP. Intraoperative blood pressure was controlled within $30 \%$ of the base value. When the blood pressure was lower than $30 \%$ of baseline value, phenylephrine was administered at 20 40ug or $0.02 \sim 0.1 \mathrm{ug} \mathrm{kg}^{-1} \cdot \mathrm{min}^{-1}$. Nitroglycerin was administered when blood pressure was higher than $30 \%$ of the base value. Atropine $0.5 \mathrm{mg}$ was administered when heart rate was below $50 \mathrm{bpm}$. No inhalation anesthetic was used and $5 \mathrm{mg}$ tropisetron was administered at about 15 minutes before the end of the operation.

The infusion of intravenous anesthetics was stopped at the end of the operation in both groups. When the patient established regular breathing with adequate ventilation, and be able to obey commands, extubation was performed.

An MMSE was assessed at the preoperative patient's visit and the day after surgery by a blinded anesthesiologist.

Blood samples were taken before anesthesia, after extubation and the day after operation, respectively. After centrifugation ( 15 minutes at $2000 \mathrm{rpm}$ ), serum samples were stored at $-70{ }^{\circ} \mathrm{C}$ for long-term storage. Serum GFAP and S100B levels were measured in duplicate manner for each sample using a commercial ELISA.

Data collection

Outcomes

The global score (GS) can reflect the overall performances of the closed-loop infusion system, including the proportion of time of adequate anesthesia (BIS between 40 and 60 ), and the fluctuation of BIS.

Therefore, GS was selected as the primary outcome. The parameters were calculated as follows: performance error (PE) was defined as the difference between the actual value and the set value:

$$
\text { PEij= }\left(\frac{\text { BISactualij-BISset }}{\text { BISset }}\right) \times 100
$$

Median performance error (MDPE):

MDPEi $=$ Median $[$ PEij,j $=1, \ldots, N i]$ 
Median absolute performance error (MDAPE):

MDAPEi $=$ Median $[|P E i j|, j=1, \ldots, N i]$

Wobble reflects the intraindividual variability in $\mathrm{PE}$ :

Wobbei $=[\mid$ PEij-MDPEi|, j = 1,..,Ni $]$

$\mathrm{i}=$ subject number; $\mathrm{j}=\mathrm{j}$ th (one) measurement of observation period; $\mathrm{N}=$ total number of measurements during the observation period.

Global score (GS) was calculated using the formula:

$$
G S=\frac{\text { MDAPE }+ \text { Wobble }}{\% \text { of time BIS between } 40 \text { and } 60}
$$

Lower MDAPE, lower Wobble, and higher proportion of time of BIS between 40 and 60, would result in a lower GS, which was represented better performances of the infusion system.

Other primary outcomes, which were collected automatically by the data-collecting software provided by Beijing slgo Medical Technology Co. Ltd, included: the percentage of adequate anesthesia (BIS between 40 and 60$)$, overshoot (BIS < 40) and undershoot (BIS > 60) periods; the adjustment times per hour for control of adequate anesthesia.

Secondary outcomes included doses of propofol, remifentanil, and the endotracheal tube removal time (from the end of the infusion of intravenous anesthetics to the removal of the endotracheal tube), patients' MAP, HR, BIS at T1 (5 minutes after intubation), T2 (10 minutes after intubation), T3 (5 minutes after adjusting to $\mathrm{BCP}$ ), T4 (10 minutes after adjusting to BCP), T5 (15 minutes after adjusting to $\mathrm{BCP}$ ), and T6 (20 minutes after adjusting to BCP), the MMSE scores of the day before operation and the day after operation, the serum concentration of GFAP and S100B protein.

\section{Statistical analysis}

SPSS 17.0 was used for statistical analysis. All statistical analyses were two-sided t test and a P-value < 0.05 was considered statistically significant. Categorical variables, expressed as numbers (frequencies), were compared using the $\chi^{2}$ test or one-way ANOVA followed by Fisher test. Continuous variables were presented as means (standard deviation) or medians (25th percentile; 75th percentile). And comparisons between the two groups were performed using unpaired Student's t-tests or Manne-Whitney U-tests as appropriate.

\section{Results}


Of the 120 recruited patients, 2 patients were excluded from each group, due to the use of inhalation anesthetics (Figure 1). There was no significant demographic difference between the two groups (Table 1). And in the induction phase, patients' characteristics were also similar between the two groups.

The GS were $25.54 \pm 9.94$ in group $C$ and $37.48 \pm 16.31$ in group 0 during the maintenance phase, respectively $(p<0.05)$ (Table 2$)$. And the mean BIS were $47.31 \pm 2.72$ in group $C$ and $48.95 \pm 3.90$ in group 0 during the maintenance phase, respectively $(p<0.05)$. As for the proportion of time of BIS between 40 and 60 , the higher proportions were found in group $C(79.62 \pm 6.75 \%)$, while the lower were observed in group $0(72.02 \pm 13.15 \%)(p<0.05)$. Meanwhile, the percentage of overshoot $(B I S<40)$ periods was lower in group $C(11.50 \pm 6.03 \%)$ than in group $0(14.54 \pm 10.53 \%)$. And the percentage time of undershoot (BIS>60) periods was lower in group C $(8.87 \pm 6.02 \%)$ than in group $0(13.45 \pm 11.92 \%)$ (Table 2$)$.

The mean consumption of propofol were $13.88 \pm 3.76 \mathrm{mg} / \mathrm{kg}$ and $15.25 \pm 5.11 \mathrm{mg} / \mathrm{kg}$ in group $\mathrm{C}$ and group 0 during the maintenance phase, respectively $(p<0.05)$ (Table 3$)$. To maintain the BIS value in an appropriate range during anesthesia, propofol was regulated more frequently in group $C(27.44 \pm 9.56$ times/hr) than in group $0(7.33 \pm 3.11$ times $/ \mathrm{hr})(\mathrm{p}<0.05)$. The induction time, the maintenance time, the consumption of remifentanil, rocuronium and vasoactive drugs were similar in the two groups. Tracheal extubation time (from the end of the infusion of intravenous anesthetics to the time of endotracheal tube removal) were $10.51 \pm 2.72$ and $11.01 \pm 3.34$ minutes in group $C$ and group 0 , respectively $(p>0.05)$ (Table 3).

There was no statistically significant difference in the MAP, HR, and BIS between the two groups at any time point (Figure 2).

The MMSE scores were similar on the day before surgery and the day after surgery between the two groups, and no significant differences were found between the two groups at any time point when comparing the GFAP and S100B levels (Table 4).

\section{Discussion}

Previous studies have shown that there is a significant decrease in BIS values in head-up position compared with neutral position during general anesthesia[7]. It means that patient's position during anesthesia may affect the BIS values, which may be related to decrease cerebral blood flow ${ }^{[4]}$. Overshoot anesthesia has been reported to cause a significant decrease in cerebral blood flow due to the overdosage of propofol[8]. Brain ischemia and transient visual loss caused by decreased cerebral blood flow have been documented in patients who have undergone shoulder surgery in the $\mathrm{BCP}^{[9-14]}$. Although the cause was unclear, intraoperative cerebral hypoperfusion may be considered to be a high-risk factor.

Our study was that avoid over-shoot anesthesia caused by over-dosage of propofol in shoulder arthroscopy in the BCP, to minimizes the risk of cerebral hypoperfusion. Previous studies have shown that 
low BIS may increase postoperative mortality. A prospective observational study of 1,046 non-cardiac surgery patients by Monk et al.[15] found that cumulative time of over-shoot anesthesia can predict mortality within 1 year, and the longer was the cumulative time of over-shoot, the higher the mortality rate was to be. A retrospective study of 4,352 cases by Lindholm et al.[16], similar to Monk et al., found that cumulative time of over-shoot anesthesia was predictive of mortality within 2 years in the absence of patients with malignant tumors. In our study, closed-loop TCl system reduced the incidence of over-shoot anesthesia period. At the same time, the proportion of time of BIS between 40 and 60 , which was regarded as appropriate anesthesia, was longer in group $C$ than in group 0 , though the mean BIS was lower in group $\mathrm{C}$ than in group $\mathrm{O}$. Similarly, the GS of group $\mathrm{C}$ was observed lower than that in group 0 . Meanwhile, the less usages of propofol were observed in group $C$ than in group 0 , suggesting that the regulation of propofol was more accurate in group $\mathrm{C}$. Through the analysis of the infusion system, it was found that the regulation of propofol can be about $28.2 \pm 9.6$ times/hour in group $C$, which is impossible to perform manually.

Endotracheal extubation time is one of the parameters to measure the recovery quality of patients. In our study, endotracheal extubation time was not statistically significant, suggesting that the recovery quality was comparable in the two groups. Then, the brachial plexus nerve block in both groups may provide adequate analgesic effect, and the less dosages of opioids were used than other studies (for example, $11.14 \pm 3.08 \mu \mathrm{g} \cdot \mathrm{kg}^{-1} \cdot \mathrm{h}^{-1}$ in group $C$ and $11.05 \pm 3.30 \mu \mathrm{g}^{\circ} \mathrm{kg}^{-1} \cdot \mathrm{h}^{-1}$ in group 0 in Liu's study[17]; the doses of remifentanil in our study was $0.11 \pm 0.03 \mu \mathrm{g} \cdot \mathrm{kg}^{-1} \cdot \mathrm{min}^{-1}$ in both groups), which is conducive to rapid and stable recovery of patients.

The mean dose of propofol in group $\mathrm{C}$ was less than group $\mathrm{O}$ during the maintenance phase, but the results of this study showed that none of the patients in the two groups had intraoperative awareness, postoperative cognitive dysfunction, or brain ischemia. It may be because only ASA I/II patients were selected, and underwent surgery for no more than 3 hours under BIS monitoring.

A weakness of this study was lack of intraoperative cerebral blood flow monitoring. Due to the limitation of surgical position placement, the probe of near infrared reflectance spectroscopy cannot be placed on the forehead. Therefore, the relationship between cerebral blood flow and BIS cannot be evaluated directly.

\section{Conclusions}

In the anesthesia maintenance stage, compared with open-loop $\mathrm{TCl}$, the closed-loop TCl of propofol guided by BIS shortened the time of BIS $<40$, reduce the dosage of propofol, and did not increase the incidence of postoperative cognitive dysfunction and intraoperative hemodynamic fluctuations. To verify the advantage of the close-loop of $\mathrm{TCl}$ for this kind of surgery reported in our study, researches with large sample size would be necessary.

\section{Abbreviations}


ASA

American Society of Anesthesiologists

BCP

Beach chair position

BIS

Bispectral index

ECG

Electrocardiogram

EEG

Electroencephalographic

ELISA

Enzyme linked immunosorbent assay

GFAP

Glial fibrillary acidic protein

GS

Global score

HR

Heart rate

IBP

Invasive blood pressure

MAP

Mean arterial pressure

MDPE

Median performance error

MDAPE

Median absolute performance error

MMSE

Mini-mental state examination

MRI

Magnetic resonance imaging

NIBP

Non-invasive blood pressure

PE

Performance error

$\mathrm{SpO} 2$

Pulse oximetry

$\mathrm{TCl}$

Target controlled infusion

TIVA

Total intravenous anesthesia 


\section{Declarations}

Author information

Affiliations

Department of Anesthesiology, Shenzhen University First Affiliated Hospital, Shenzhen, Guangdong, China

Zhao Zhao, Jun-jie Li (co-first authors)

Department of Anesthesiology, Shenzhen University First Affiliated Hospital, Shenzhen, Guangdong, China

Nan-bo Luo, Fang Yang, Han Yang, Xi-ping Yang

Department of Sports Medicine, Shenzhen University First Affiliated Hospital, Shenzhen, Guangdong, China

Liang-quan Peng, Wei Lu, Da-ping Wang

Department of Gynaecology, Shenzhen University First Affiliated Hospital, Shenzhen, Guangdong, China

Fang Guangguang

Department of Anesthesiology, Shenzhen University First Affiliated Hospital, 3002 Sungang West Road, Shenzhen, Guangdong, China

Zhi-heng Liu (corresponding author)

\section{Contributions}

Concept/design: J-jL, D-pW, Z-hL; Data analysis/interpretation: N-bL, FY, HY, L-qP; Drafting article: J-jL, ZZ; Critical revision of article: J-jL, ZZ, WL, Z-hL; Directing clinical research: G-gF; Approval of the article: J-jL, ZZ, N-bL, FY, HH, X-pY, L-qP, WL, G-gF, D-pW, Z-hL; Statistics: HH, X-pY; Data collection: N-bL, FY, L-qP. All authors read and approved the final manuscript.

Corresponding author

Correspondence to Zhi-heng Liu. 
Ethics declarations

Ethics approval and consent to participate

The study was approved by the Ethics Committee of the Second People's Hospital of Shenzhen (2017082203), and registered at Chictr.org.cn.(ChiCTR-INR-17012557). Informed written consent was obtained from all patients.

Consent for publication

Not applicable.

Competing interests

The authors declare that they have no competing interests.

Acknowledgements

The authors thank slgo Medical, which provided closed-loop target controlled infusion system.

Availability of data and materials

The datasets used and/or analyzed during the current study are available from the corresponding author on reasonable request.

Funding

This research did not receive any specific grant from funding agencies in the public, commercial, or notfor-profit sectors.

\section{References}

[1] B. G. Fahy and D. F. Chau, "The Technology of Processed Electroencephalogram Monitoring Devices for Assessment of Depth of Anesthesia," Anesth Analg, vol. 126, pp. 111-117, Jan 2018. 

coadministration of propofol and remifentanil guided by bispectral index: a randomized multicenter study," Anesth Analg, vol. 112, pp. 546-57, Mar 2011.

[3] V. Mahajan, T. Samra, and G. D. Puri, "Anaesthetic depth control using closed loop anaesthesia delivery system vs. target controlled infusion in patients with moderate to severe left ventricular systolic dysfunction," Journal of Clinical Anesthesia, vol. 42, pp. 106-113, Nov 2017.

[4] N. Alperin, S. H. Lee, M. Mazda, S. G. Hushek, B. Roitberg, J. Goddwin, et al., "Evidence for the importance of extracranial venous flow in patients with idiopathic intracranial hypertension (IIH)," Acta Neurochir Suppl, vol. 95, pp. 129-32, 2005.

[5] J. F. Coetzee, J. B. Glen, C. A. Wium, and L. Boshoff, "Pharmacokinetic model selection for target controlled infusions of propofol. Assessment of three parameter sets," Anesthesiology, vol. 82, pp. 132845, Jun 1995.

[6] C. F. Minto, T. W. Schnider, T. D. Egan, E. Youngs, H. J. Lemmens, P. L. Gambus, et al., "Influence of age and gender on the pharmacokinetics and pharmacodynamics of remifentanil. I. Model development," Anesthesiology, vol. 86, pp. 10-23, Jan 1997.

[7] A. M. Kaki and W. A. Almarakbi, "Does patient position influence the reading of the bispectral index monitor?," Anesth Analg, vol. 109, pp. 1843-6, Dec 2009.

[8] A. T. Vandesteene, V; Engelman, E; de Rood, $M$; , "Effect of propofol on cerebral blood flow and metabolism in man," Anaesthesia, vol. 43, pp. 42-43, 1988.

[9] M. T. Bhatti and F. K. Enneking, "Visual loss and ophthalmoplegia after shoulder surgery," Anesth Analg, vol. 96, pp. 899-902, table of contents, Mar 2003.

[10] C. Dippmann, S. Winge, and H. B. Nielsen, "Severe cerebral desaturation during shoulder arthroscopy in the beach-chair position," Arthroscopy, vol. 26, pp. S148-50, Sep 2010.

[11] J. C. Drummond, R. R. Lee, and J. P. Howell, Jr., "Focal cerebral ischemia after surgery in the "beach chair" position: the role of a congenital variation of circle of Willis anatomy," Anesth Analg, vol. 114, pp. 1301-3, Jun 2012.

[12] G. S. Murphy, J. W. Szokol, J. H. Marymont, S. B. Greenberg, M. J. Avram, J. S. Vender, et al., "Cerebral oxygen desaturation events assessed by near-infrared spectroscopy during shoulder arthroscopy in the beach chair and lateral decubitus positions," Anesth Analg, vol. 111, pp. 496-505, Aug 2010.

[13] A. Papadonikolakis, E. R. Wiesler, M. A. Olympio, and G. G. Poehling, "Avoiding catastrophic complications of stroke and death related to shoulder surgery in the sitting position," Arthroscopy, vol. 24, pp. 481-2, Apr 2008. 
[14] A. Pohl and D. J. Cullen, "Cerebral ischemia during shoulder surgery in the upright position: a case series," J Clin Anesth, vol. 17, pp. 463-9, Sep 2005.

[15] T. G. Monk, V. Saini, B. C. Weldon, and J. C. Sigl, "Anesthetic management and one-year mortality after noncardiac surgery," Anesth Analg, vol. 100, pp. 4-10, Jan 2005.

[16] M. L. Lindholm, S. Traff, F. Granath, S. D. Greenwald, A. Ekbom, C. Lennmarken, et al., "Mortality within 2 years after surgery in relation to low intraoperative bispectral index values and preexisting malignant disease," Anesth Analg, vol. 108, pp. 508-12, Feb 2009.

[17] Y. Liu, M. Li, D. Yang, X. Zhang, A. Wu, S. Yao, et al., "Closed-loop control better than open-loop control of profofol TCl guided by BIS: a randomized, controlled, multicenter clinical trial to evaluate the CONCERT-CL closed-loop system," PLoS One, vol. 10, p. e0123862, 2015.

\section{Tables}

Table 1 Demographic characteristics of patients in the group $\mathrm{C}$ and the group 0.

\begin{tabular}{|c|c|c|c|c|}
\hline & & Open-loop(n=58) & Closed-loop $(n=58)$ & $\begin{array}{l}P \text { - } \\
\text { values }\end{array}$ \\
\hline Gender & Male(\%) & $30(52)$ & $34(59)$ & 0.577 \\
\hline Age & (years) & $47(40.5 ; 54)$ & $45(30 ; 52.25)$ & 0.058 \\
\hline Height & $(\mathrm{m})$ & $1.67(0.08)$ & $1.67(0.07)$ & 0.909 \\
\hline Weight & $(\mathrm{kg})$ & $64(58.75 ; 72.00)$ & $67(60.75 ; 75.50)$ & 0.789 \\
\hline BMI & $\left(\mathrm{kg} / \mathrm{m}^{2}\right)$ & $22.86(2.45)$ & $23.78(2.94)$ & 0.567 \\
\hline \multirow[t]{2}{*}{ ASA classification } & $\mathrm{I}(\%)$ & $29(50)$ & $25(43)$ & \multirow[t]{2}{*}{0.706} \\
\hline & $\|(\%)$ & $29(50)$ & $33(57)$ & \\
\hline \multicolumn{5}{|c|}{$\begin{array}{l}\text { Summary characteristics of intraoperative measurements presented as } \mathrm{n}(\%) \text { and means } \\
\text { (standard deviation) or medians (25th percentile; } 75 \text { th percentile). All P-values are for } \\
\text { unpaired Student's t-tests or Manne Whitney U-tests as appropriate. }\end{array}$} \\
\hline \multicolumn{5}{|c|}{$\mathrm{BMI}=$ Body Mass Index } \\
\hline
\end{tabular}




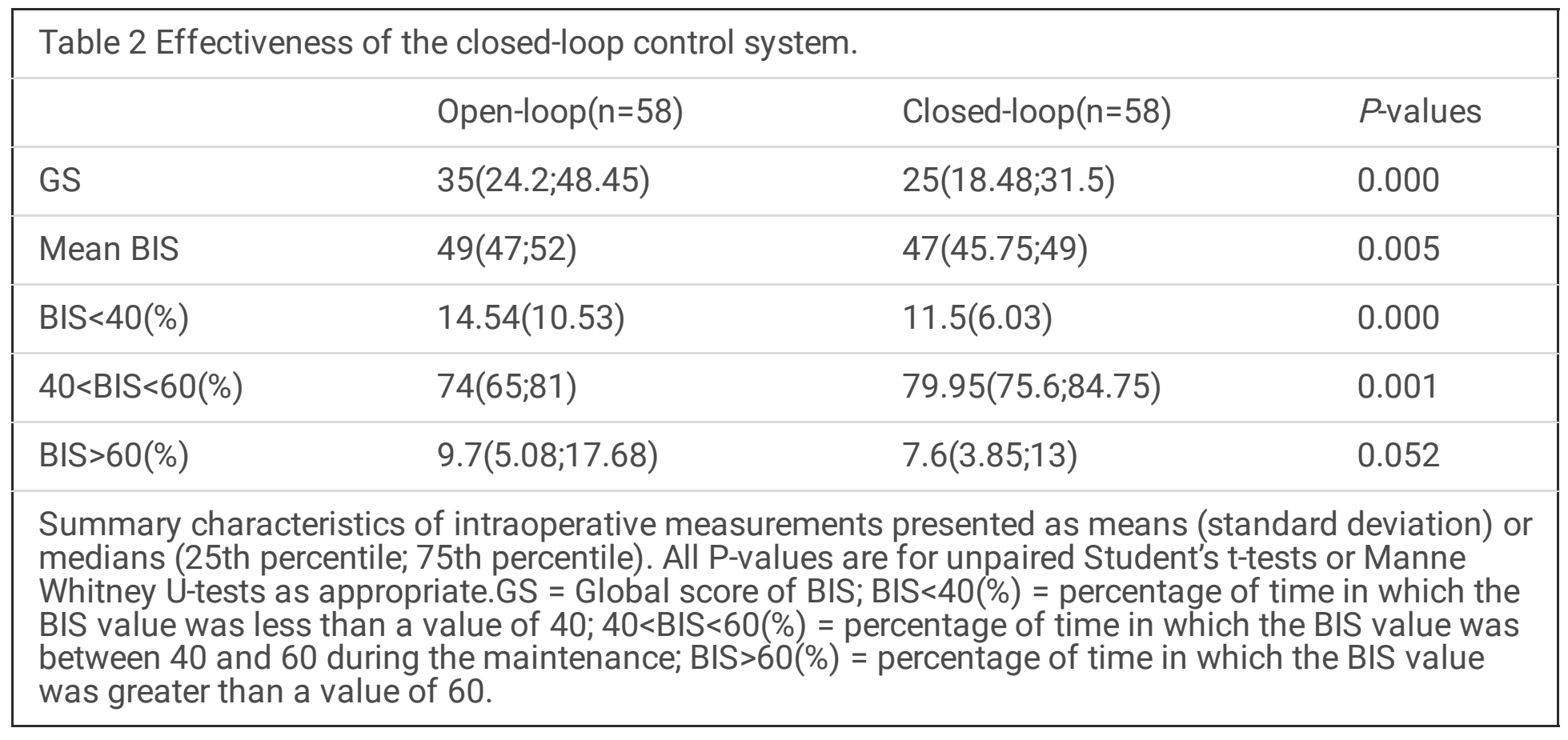


Table 3. Comparison of anesthetic procedures between the two groups.

\begin{tabular}{|c|c|c|c|c|}
\hline & & $\begin{array}{l}\text { Open- } \\
\text { loop }(n=58)\end{array}$ & Closed-loop $(n=58)$ & $\begin{array}{l}P- \\
\text { values }\end{array}$ \\
\hline Induction time & $(\min )$ & $4.24(1.96)$ & $5.18(2.25)$ & 0.219 \\
\hline Maintenance time & $(\min )$ & 159.13(43.72) & $154.69(38.16)$ & 0.649 \\
\hline Extubation time & $(\min )$ & $11.13(8.07)$ & $10.70(8.49 ; 12.56)$ & 0.386 \\
\hline \multicolumn{5}{|l|}{ Propofol } \\
\hline Mean dose of induction time & $(\mathrm{mg} / \mathrm{kg})$ & $1.82(0.45)$ & $1.89(0.51)$ & 0.296 \\
\hline $\begin{array}{l}\text { Mean dose of maintenance } \\
\text { time }\end{array}$ & $(\mathrm{mg} / \mathrm{kg})$ & $15.25(5.11)$ & $13.88(3.76)$ & 0.026 \\
\hline Adjusted times & $(/ \mathrm{h})$ & $7.21(5.55 ; 9.42)$ & $27.69(21.46 ; 34.44)$ & 0.000 \\
\hline \multicolumn{5}{|l|}{ Remifentanil } \\
\hline Mean dose & $\left(\mu \mathrm{g} \cdot \mathrm{kg}^{-1} \cdot \mathrm{min}^{-1}\right)$ & $0.11(0.03)$ & $0.10(0.03)$ & 0.908 \\
\hline Adjusted times & $(/ \mathrm{h})$ & $2.32(0.65)$ & $2.45(0.84)$ & 0.052 \\
\hline Mean dose of rocuronium & $(\mathrm{mg} / \mathrm{kg})$ & $0.70(0.08)$ & $0.69(0.08)$ & 0.923 \\
\hline Phenylephrine & $(\%)$ & $46(79)$ & $48(83)$ & 0.813 \\
\hline Atropine & $(\%)$ & $24(41)$ & $18(31)$ & 0.334 \\
\hline Nitroglycerin & $(\%)$ & 0 & 0 & \\
\hline
\end{tabular}


Table 4. Comparison of MMSE scores, GFAP and S100 $\beta$ protein concentrations between the two groups.

\begin{tabular}{|c|c|c|c|c|c|}
\hline & & Open-loop $(n=58)$ & Closed-loop $(n=58)$ & $P$-values & \\
\hline $\begin{array}{l}\text { MMSE scores before } \\
\text { surgery }\end{array}$ & & $26.64(1.82)$ & $26.53(2.02)$ & 0.684 & \\
\hline MMSE scores after surge & & $26.52(1.55)$ & $26.28(1.50)$ & 0.734 & \\
\hline $\begin{array}{l}\text { Intraoperative awareness } \\
\text { rate }\end{array}$ & & 0 & 0 & & \\
\hline \multirow[t]{3}{*}{$\mathrm{GFAP} \rrbracket \mathrm{ng} / \mathrm{ml} \rrbracket$} & T0 & $0.87(0.35)$ & $1.00(0.39)$ & & 0.152 \\
\hline & T7 & $1.19(0.46)$ & $0.92(0.45)$ & & 0.772 \\
\hline & T8 & $0.60(0.27)$ & $0.92(0.30)$ & & 0.247 \\
\hline \multirow[t]{3}{*}{$\mathrm{S} 100 \beta \bigotimes \mathrm{pg} / \mathrm{ml} \square$} & TO & $32.08(16.13)$ & $30.14(14.07)$ & & 0.327 \\
\hline & T7 & $71.20(24.94)$ & $80.96(27.73)$ & & 0.242 \\
\hline & T8 & $32.16(13.02)$ & $23.66(13.31)$ & & 0.863 \\
\hline \multicolumn{6}{|c|}{$\begin{array}{l}\text { Summary characteristics of intraoperative measurements presented as means (standard } \\
\text { deviation) or medians ( } 25 \text { th percentile; } 75 \text { th percentile). All P-values are for unpaired } \\
\text { Student's t-tests or ManneWhitney U-tests as appropriate. }\end{array}$} \\
\hline
\end{tabular}

\section{Figures}




\section{CONSORT 2010 Flow Diagram}

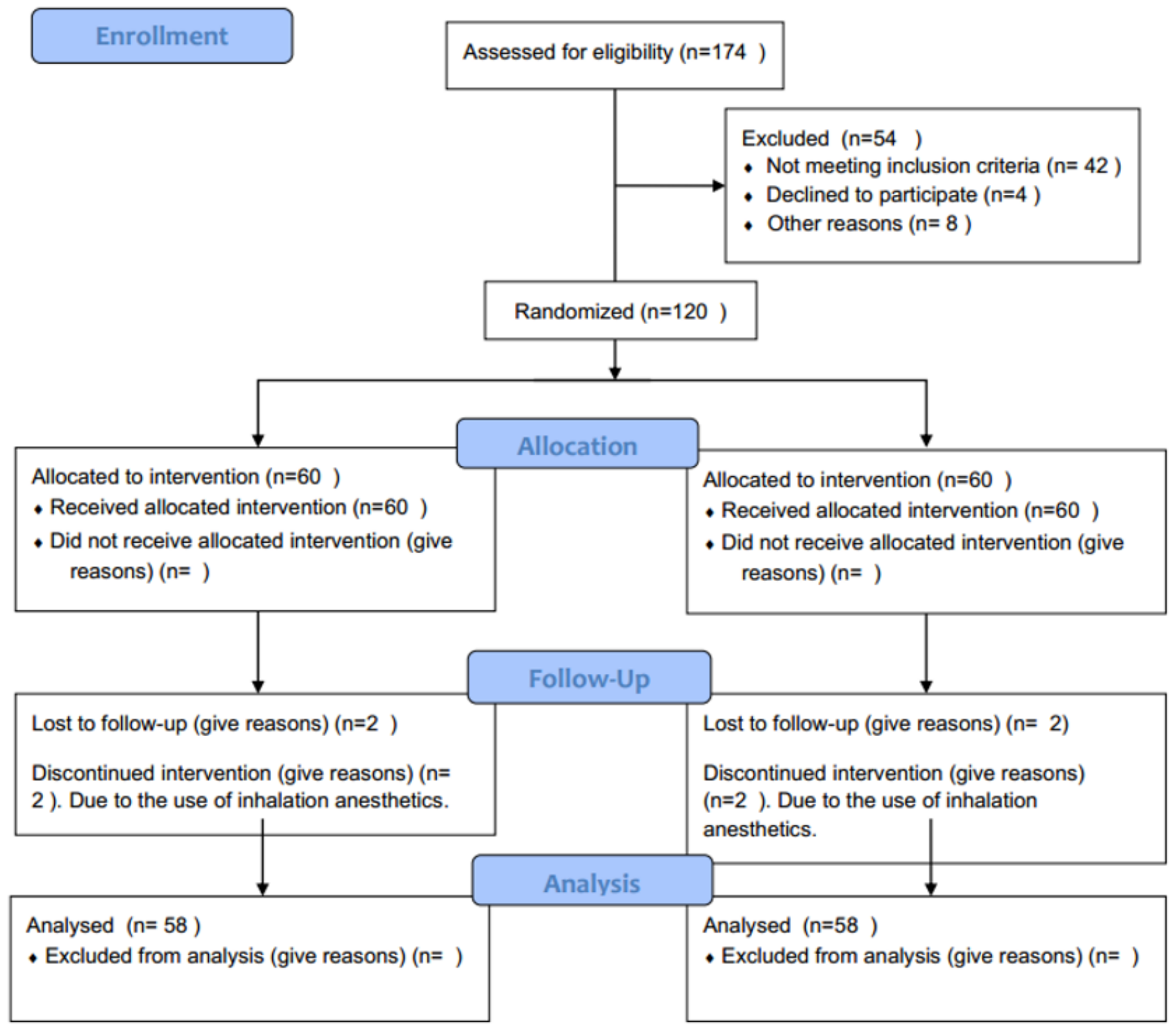

\section{Figure 1}

Study flowchart 

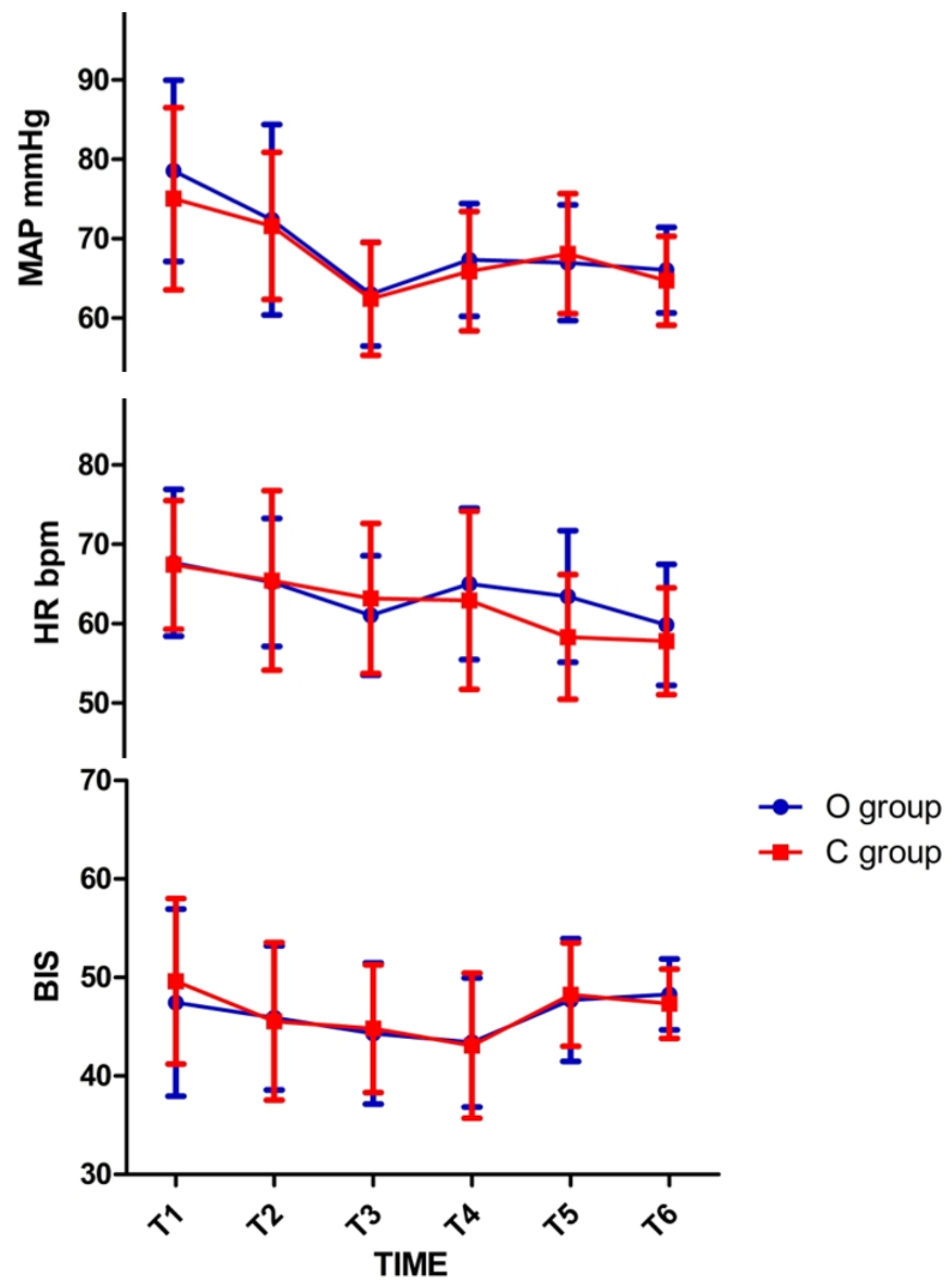

Figure 2

There was no statistically significant difference in the MAP, HR, and BIS between the two groups at any time point

Supplementary Files 
This is a list of supplementary files associated with this preprint. Click to download.

- Appendix.docx

- CONSORT2010Checklist.doc 